\title{
SPLINTERS SÃO CRUZAMENTOS DE CRUZAMENTOS? REPENSANDO O ESTATUTO DESSE CONSTITUINTE EM PORTUGUÊS
}

Carlos Alexandre GONÇALVES ${ }^{1}$ Wallace Bezerra de CARVALHO ${ }^{2}$ Katia Emmerick ANDRADE ${ }^{3}$

\begin{abstract}
Resumo: Constitui objetivo deste artigo checar, para o português, a validade da proposta de Tomaszewicz (2008), para quem splinters não constituem unidades de análise morfológica, sendo, na verdade, cruzamentos de cruzamentos. Para tanto, tomamos por base as análises otimalistas de Gonçalves (2005) e Andrade (2008), sobre cruzamento vocabular, observando em que medida formações mais recentes, com o que vimos chamando de splinters (GONÇALVES, 2011; GONÇALVES, 2013; ANDRADE, 2013), conseguem ser bem sucedidas frente ao ranking de restrições proposto. Desse modo, procuramos conferir, com dados do português do Brasil, se a ideia de que splinters são cruzamentos de cruzamentos de fato se sustenta em nossa língua.
\end{abstract}

Palavras-chave: Morfologia. Cruzamento. Teoria da Otimalidade. Splinter.

\section{Introdução}

Casos fronteiriços geralmente são de difícil definição e essa situação é ainda mais delicada quando lidamos com questões morfológicas. Por conta disso, existem muitas polêmicas em relação ao estatuto de diversas unidades, o que atinge naturalmente o conceito de splinter, tendo em vista que essa classe de formativos só recentemente vem recebendo a devida atenção dos pesquisadores da área.

Bauer (2005, p. 105, grifo nosso) assim se posiciona em relação aos splinters: "por splinter entendo um fragmento de palavra usado repetidamente na formação de novas palavras". Ao afirmar que splinters surgem do processo de blending (cruzamento vocabular), Bauer (op. cit., p. 105) ressalta que o emprego que faz do termo "é uma pequena extensão do

\footnotetext{
${ }^{1}$ Professor Associado da Faculdade de Letras da UFRJ. E-mail: carlexandre@bol.com.br

${ }^{2}$ Graduando em Letras Vernáculas. Bolsista do CNPq. E-mail: wallacebcarvalho@gmail.com

${ }^{3}$ Professor Adjunto do Instituto Multidisciplinar da UFRRJ.E-mail: kemmericka@ hotmail.com
} 
uso encontrado em Adams (1973, p. 142)”. A “pequena extensão” a que se refere o autor é a recorrência de tais partículas. Por isso mesmo, em Bauer (2005), splinter deixa de ser concebido apenas como uma porção aleatória de palavras para ser interpretado como uma categoria morfológica com estatuto parecido com o de afixos, já que splinters são agora encarados como entidades que podem levar à criação de novos formativos. Essa ideia aparece bem resumida na seguinte definição que Bauer (2004, p. 77) faz para os splinters em seu Glossary of Morphology:

Splinter é uma parte de uma palavra que, devido a algumas reanálises da estrutura da palavra original, é interpretada como significativa e posteriormente utilizada na criação de novas palavras. Como exemplo familiar, considere a palavra 'alcoholic'. Em termos morfológicos, esse vocábulo é dividido em 'alcohol' e -ic. Mas essa palavra foi reanalisada como alc-oholic, e o novo splinter -oholic (variavelmente soletrado), em seguida, reocorre em palavras como chocoholic, spendaholic e shopoholic.

No artigo "Novel words with final combining forms in English. A case for blends in Word formation", de Tomaszewicz (2008), a autora fornece evidências empíricas contra a existência de splinters em inglês. Para tanto, apresenta diferentes tipos de formativos tidos como formas combinatórias finais ${ }^{4}$, para, enfim, (a) focar em um desses elementos (as partículas não morfêmicas, casos típicos de splinters) e (b) argumentar contra a sua existência, afirmando que não passam de blends de blends (cruzamentos de cruzamentos). Por exemplo, para ela, uma forma como "sucolé" ("sacolé feito de suco de fruta natural") seria um cruzamento de outro cruzamento, "sacolé" ("picolé em forma de saco"). Com o objetivo de negar a relevância da noção de splinter para os estudos morfológicos, Tomaszewicz (op. cit.) baseia-se na Teoria da Otimalidade (doravante TO) em sua versão de Correspondência Output-Output (TC), na linha de Benua (1995) e McCarthy e Prince (1995), mostrando que

\footnotetext{
${ }^{4}$ De acordo com Kastovsky (2009, p. 02), a expressão forma combinatória, amplamente utilizada na literatura morfológica das últimas décadas do século passado, veio do Oxford English Dictionary. De acordo com o autor, "o termo foi adotado para nomear parte de empréstimos do grego e do latim ou formações do inglês que não se utilizam propriamente de palavras nem são facilmente identificáveis com afixos" (KASTOVSKY, 2009, p. 02). Desse modo, é usualmente empregado para descrever elementos morfológicos de natureza variada (GONÇALVES, 2011, p. 67-68): "a) radicais gregos e latinos que se fixaram numa borda específica da palavra, comportando-se, por isso mesmo, como prefixos (p. ex., tele-, em 'telepizza', 'telenovela' e 'televendas') ou como sufixos (p. ex., -cracia, em 'burrocracia' e 'dilmocracia'); b) elementos neoclássicos encontrados em diferentes posições na estrutura da palavra, como 'antropo' ('filantropia'; 'antropófago') e 'fone' ('telefone'; 'fonologia'), denominados de confixos por Martinet (1979), em função da oscilação posicional; c) porções fonológicas oriundas de truncamento (clipping), aqui entendido como processo de redução (morfologia subtrativa) em que uma parte não-morfêmica passa a valer pelo todo, a exemplo de expo- ('expo-noivas', 'expobebê', 'expo-filhotes'), truncamento de 'exposição'; e d) itens morfológicos resultantes de cruzamentos vocabulares, a exemplo de -drasta ('mãedrasta', 'sogradrasta' $<<$ 'madrasta') e -trocínio ('tiotrocínio', 'avôtrocínio' << 'patrocínio')”. A autora, portanto, aborda não apenas o que aqui chamamos de splinter, mas também outros tipos de partículas bastante diferentes em forma e função.
} 
todas as formações com essas alegadas unidades emergem na hierarquia de restrições que elabora, com base na proposta de Piñeros (2002).

Constitui objetivo deste artigo checar a validade da proposta de Tomaszewicz (2008) para o português. Para tanto, tomamos por base as análises otimalistas de Gonçalves (2005) e Andrade (2008), sobre cruzamento vocabular, observando em que medida formações mais recentes, com o que vimos chamando de splinters (GONÇALVES, 2011; GONÇALVES, 2013; ANDRADE, 2014), conseguem ser bem-sucedidas frente ao ranking de restrições proposto. Desse modo, procuramos conferir, com dados do português do Brasil, se a ideia de que splinters são cruzamentos de cruzamentos (TOMASZEWICZ, 2008) de fato se sustenta em nossa língua. Obviamente, deixamos de lado análises sobre cruzamentos em português que se pautem em outros modelos teóricos, pois, por coerência de análise, seus resultados são outros e nada podem contribuir para o objetivo central deste texto: discutir a noção de splinter, sequer referenciada na maioria das abordagens sobre blends em nossa língua. Além disso, para traçar um paralelo com a proposta de Tomaszewicz (op. cit.), de orientação otimalista, é natural que nos pautemos em outras análises igualmente otimalistas.

Utilizamos, para tanto, não apenas os dados de cruzamentos de Gonçalves (2005) e Andrade (2008), mas, sobretudo, as formações analisadas em Carvalho e Gonçalves (2015), sobre as novas construções cunhadas com as partículas piri- e -guete, ambas originadas da palavra recém-criada 'periguete', "mulher vulgar, trajada com roupas extravagantes", a exemplo de 'piricrente' ("evangélica trajada com roupas não convenientes a um templo religioso") e 'vovóguete' ("vovó que se veste extravagantemente"). Em Carvalho e Gonçalves (op. cit.), ressalta-se que, até onde se conhece, essa foi a primeira palavra a dar origem a dois splinters. Com base nesses dados, procuramos comprovar que as construções piri-X e X-guete não constituem cruzamentos de cruzamentos, sendo, antes, produtos do acréscimo dos splinters piri- e -guete nas posições inicial e final, respectivamente, a exemplo de 'pirigótica' e 'coroguete'.

O texto se estrutura da seguinte maneira: na próxima seção, resumimos a proposta de Tomaszewicz (2008), retomando os principais pontos de sua análise. Logo após, destacamos a solução otimalista para o tratamento de cruzamentos vocabulares em português, ressaltando que o conjunto de restrições é praticamente o mesmo usado pela autora. Na sequência, apresentamos os dados que embasam a análise: as formações piri-X e X-guete. Por fim, concluímos o texto, mostrando se realmente a noção de splinter pode ser dispensada, como sugere Tomaszewicz (2008). 


\section{A proposta de Tomaszewicz (2008)}

Iniciando seu texto, Tomaszewicz faz uma rápida incursão de como blends (cruzamentos vocabulares, doravante CV) são analisados em textos mais antigos que abordam o tema, alegando que tais propostas tratam o fenômeno do $\mathrm{CV}$ como uma categoria "altamente imprevisível, sem ou com bem pouca regularidade observável" (TOMASZEWICZ, 2008, p. 363). Logo após, visões mais recentes são apresentadas, com a autora afirmando que essas entendem o fenômeno como "manipulação de constituintes fonológicos como sílabas em cruzamentos polissilábicos” (TOMASZEWICZ, 2008, p. 364) e “segmentos em monossílabos" (TOMASZEWICZ, 2008, p. 364). Por conseguinte, a autora argumenta contra a regra $(01) \mathrm{AB}+\mathrm{CD}=\mathrm{AD}$, considerando-a geral demais e, consequentemente, insuficiente, por conta de não se mostrar sensível a uma série de características que vão além da simples sequenciação de constituintes, tais como estrutura silábica e diferentes níveis fonológicos (segmentos, sílabas, pés métricos etc.).

Tomaszewicz elicita, então, que, a partir da TO, alguns autores observam padrões e regularidades de CVs, e que, tendo como intuito dar continuidade aos trabalhos, também lança mão da versão da TO que lida com a abordagem Output-Output (Teoria da Correspondência - BENUA, 1995; MCCARTHY; PRINCE, 1995), de modo a analisar agora possíveis motivações e padrões para formas combinatórias finais.

Na primeira seção de seu trabalho, a autora discorre sobre a descrição de CVs pela TO. Dessa maneira, entende essas formações como mistura estrutural de palavras, as palavrasfonte, tendo como resultado uma única palavra que combina o significado de ambas as fontes. Tomaszewicz alega que CVs são estruturalmente próximos de compostos, sendo realizados, porém, em um único domínio fonológico, como uma única palavra prosódica (PWd Prosodic Word). Dessa forma, Tomaszewicz, seguindo Piñeros (2002), estipula que um CV produz uma única palavra prosódica, como ilustrado a seguir, retirado de Gonçalves (2005, p. 3), em que MWd abrevia Morphological Word (palavra morfológica), o asterisco representa um constituinte complexo e linhas pontilhadas, elementos compartilhados: 


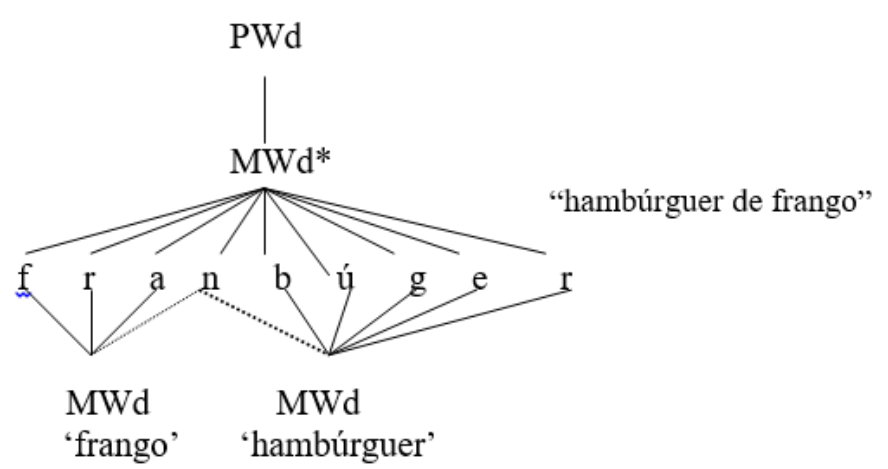

A seguir, a autora passa a apresentar a estrutura fonológica de CVs. Considera-se que essas palavras complexas são a junção de duas outras em representação fonológica de apenas uma, como em (02). Para que isso aconteça, as duas formas em questão devem possuir segmentos semelhantes, além de as bordas se alinharem com constituintes prosódicos das formas utilizadas no processo. De acordo com a autora, os segmentos compartilhados não precisam ser necessariamente idênticos, mas semelhantes, o que aumenta o alcance de possíveis formações por cruzamento. A representação abaixo mostra que apenas uma das seis margens de palavra morfológica ${ }^{5}$ aparece desalinhada no interior do cruzamento. A fusão da sigla PT (soletrada [pe'te]) com 'metralha'6 resulta em 'petralha' ("petista de pouco apreço à ética ou à moralidade pública", definição dada pelo blogueiro Reinaldo Azevedo). Somente a direita da forma de base 'PT' não se encontra alinhada; todas as demais coincidem com a esquerda ou com a direita da palavra prosódica 'petralha', o cruzamento. Nessa representação, \{ \} sinaliza margens de palavra morfológica e [ ], margens de palavra prosódica. Também aqui, linhas pontilhadas representam correspondências múltiplas. Observe-se que a consoante inicial, apesar de não idêntica, é interpretada como pertencente às duas formas de base, uma vez que a diferença entre $/ \mathrm{p} /$ e $/ \mathrm{m} /$ é mínima: consiste apenas na ausência $v$ s. presença de nasalidade.

\footnotetext{
${ }^{5}$ Cruzamentos apresentam seis margens de palavra morfológica (esquerda e direita das duas formas de base e esquerda e direita da forma resultante) e duas margens de palavra prosódica (esquerda e direita da forma resultante). Em linhas gerais, as margens de palavra morfológica coincidem com as duas margens de palavra prosódica disponíveis para o alinhamento.

${ }^{6}$ Os irmãos metralha, criação de Walt Disney, são três presidiários que perseguem a fortuna do tio Patinhas para roubá-la. A nova formação alude, portanto, a um possível esquema de corrupção envolvendo o partido.
} 


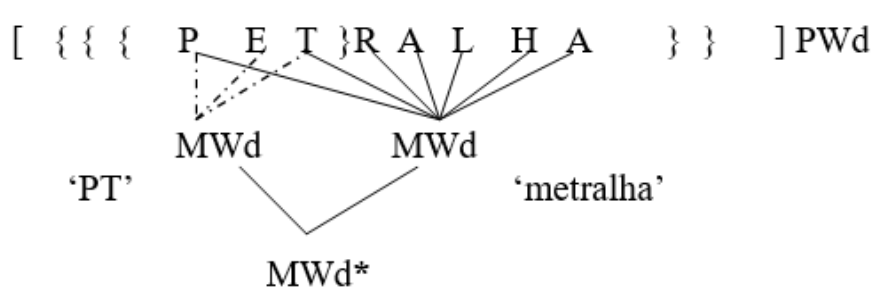

A otimização dos CVs consiste em ter uma única camada de estrutura prosódica que satisfaz a restrição de marcação dominante (04), adaptada de Piñeros (2000, p. 5).

(04) No-PWd*: No Prosodic Word recursion (não recursividade da palavra prosódica): Uma palavra prosódica não pode ser complexa.

Em palavras morfologicamente complexas, tais como compostos e cruzamentos, a restrição em (04) conflita com a restrição relativa à interface fonologia-morfologia em (05), exigindo que um membro da categoria morfológica (MCat), isto é, a Palavra morfológica (MWd), no caso de compostos e CVs, corresponda a somente uma palavra prosódica.

(05) LX = PWd (PRINCE; SMOLENSKY, 1993, p. 45): um lexema equivale a uma palavra prosódica

Cruzamentos satisfazem a restrição dominante em (04) ao custo de violar a restrição em (05). Como NO-PWd* domina $\mathrm{LX}=\mathrm{PWd}$, cruzamentos nunca se realizam conforme o esquema abaixo, típico de compostos:

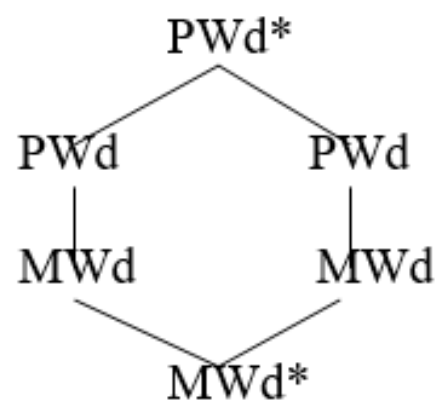

Na segunda seção de seu trabalho, Tomaszewicz discorre sobre formas combinatórias finais. Inicia apresentando a dificuldade em definir tais formas, pois, para ela, essa classe inclui (a) radicais neoclássicos (por exemplo, -ology, -ography, -naut, -phile; BAUER, 1998, p. 404-406), (b) consoantes iniciais de novos morfemas presos (por exemplo, -gate, -ware, scape; BAUER, 2001, p. 53) e (c) formas encurtadas (-(a)holic, -(a)thon, -(o)nomics; BAUER, 1998, p. 407; WARREN, 1990, p. 129). Alega que as duas primeiras são fonologicamente motivadas, enquanto as em (c), "que podem parecer oriundas de partes recorrentes de cruzamentos (BAUER, 2005, p. 503), são apenas grosseiramente identificáveis, 
porque não é possível definir seu tamanho exato, em termos de material segmental" (TOMASZEWICZ, 2008, p. 371).

No nosso entendimento, o problema está na definição do que vem a ser uma forma combinatória, pois essa classe é bastante heterogênea e, por isso mesmo, vem sendo repensada nos últimos tempos. Por exemplo, Kastovsky (2009, p. 43) mostra que essa classe "é como um arenque vermelho em morfologia; cria mais problemas que resolve". De fato, vincular radicais neoclássicos a partes de palavras não parece uma proposta interessante, pois, sem dúvida alguma, as formas em (a), acima, diferem substancialmente das em (b) e (c), que ganham recorrência e passam a funcionar como morfemas. No caso de (b), a exemplo de -nejo e -guete (casos paralelos aos do inglês, apresentados pela autora), os sufixos -ejo e -ete se associam, nesta ordem, à consoante nasal, /n/, que aparece em 'sertanejo', e à oclusiva velar /g/, constante de 'periguete', e passam a constituir unidade. No caso de (c), a variação de tamanho, como em -lé, com apenas uma sílaba, e -trocínio, com várias, é, para nós, fruto do cruzamento de onde se desprenderam, o que possibilita a combinação com novas formas, levando a outras de tamanho igualmente variado. No nosso entendimento, a noção de forma combinatória é dispensável, já que inclui unidades bastante diferentes entre si: radicais neoclássicos (caso em (a)) e splinters (casos em (b) e (c)).

De modo a fornecer evidências para a não existência de tais formas, a autora oferece, em corpus, dados que não apresentam regularidade no que se refere a radicais neoclássicos, uma vez que esses não se apresentam da mesma maneira. A partir dos dados apresentados, a autora alega que muitos são cruzamentos apenas devido à recuperabilidade possível das palavras-fonte. Tomaszewicz (2008, p. 371) sustenta sua análise com os dados abaixo, em que SF abrevia Source Form (Forma de Base) e BL, Blend (Cruzamento):

\begin{tabular}{llll} 
(07) war & go(rílla) & pa(thólogy) & $\mathrm{S}$ \\
por(nógraphy) & (tele)(gràm) & (auto) bi(ógraphy) & SF2 \\
\hline war(nógraphy) & go(rilla)(gram) & $\begin{array}{l}\text { (auto)pa(thógraphy) } \\
\text { thug }\end{array}$ & BL \\
de(mócracy) & de(mócracy) & bu(reáucracy) & SF2 \\
\hline thu(gócracy) & xe(rócracy) & xe(rócracy) & BL
\end{tabular}

Em relação a esses exemplos, com radicais neoclássicos, a autora afirma o seguinte: "pensando bem, estes últimos devem ser vistos como cruzamentos, apesar de seus sufixos 
motivados independentemente parecerem estar anexados para completar as palavras" (TOMASZEWICZ, 2008, p. 373). Não vemos problemas nos dados acima, uma vez que formações neoclássicas podem se envolver em cruzamentos, o que não necessariamente criaria splinters como 'nografia' e 'rocracia', por exemplo. Além disso, os sufixos [sic!] em (07) não "parecem estar anexados para completar as palavras"; estão ali porque uma das palavras-fonte apresenta esse constituinte, não havendo, portanto, qualquer acréscimo consonantal digno de nota, a ponto de fazer dessas formas criações com splinters. Em português, também se observam exemplos de CVs em formações neoclássicas:

(08) pilantropia 'filantropia de fachada; na verdade, uma pilantragem'

democradura 'ditadura travestida de democracia'

pedragogia 'pedagogia dura demais, como pedra'

Em 'pilantropia', por exemplo, explora-se maximamente a semelhança das bases, de modo que a maior é inteiramente preservada, se consideramos uma correspondência não idêntica entre o /p/ de 'pilantra' e o /f/ de 'filantropria', segmentos de fato muito próximos, diferindo apenas em relação ao traço [contínuo]. Isso não faria com que a sequência 'lantropia' ganhasse qualquer estatuto morfológico. Observe, na representação a seguir, que a maior parte dos segmentos fônicos é compartilhada:

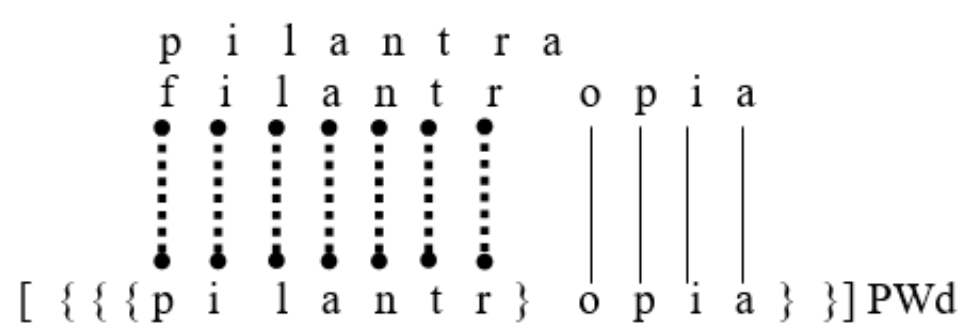

Ainda na segunda seção, são apresentados argumentos contra a existência de formas que se desprendem de outras, levando com elas seu significado (morfemas zipados). Tais formas são, para a autora, caracterizadas pela imprevisibilidade estrutural, podendo apresentar formas iniciadas ou não por vogal, serem entranhadas na base etc. É também argumentado que sufixos produtivos em inglês, língua analisada, se conectam somente a palavras completas, o que formas combinatórias não fazem. Os dados abaixo evidenciam para o português, diferentemente do que a autora sugere para o inglês, que as formas oriundas de blends podem desprender-se dos cruzamentos originais e atuar na posição de sufixos, combinando-se com palavras completas:

(10) sogradrasta, tiadrasta; (Relaciona-se a ideia de madrasta a outros parentes) quintaneja, terçaneja; (Relaciona-se a ideia de música sertaneja a dias semanais) 
avôtrocínio, tiotrocínio; (Evidencia-se o agente do patrocínio)

whiskylé, sucolé; (Relaciona-se a ideia de sacolé e seu ingrediente principal)

amigaguete, irmãguete; (Atribuição da característica "piriguete” a alguém)

ovonese, frangonese. (Receita em que se mistura um ingrediente com maionese)

Torna-se notável para a autora a emergência da forma -(a)holism em inglês por conta da forma combinatória -(a)holic, o que, para ela, também constitui argumento contra a interpretação dessas sequências como partículas independentes. Contudo, a emergência de uma segunda forma relacionada à primeira pode fornecer evidência da categorização de (a)holic como forma presa ao levarmos em consideração relações paradigmáticas em um léxico hierárquico, como em Booij (2010). Podemos considerar tal proposta por conta de, pragmaticamente, a tendência a um indivíduo ser $[[\mathrm{X}](\mathrm{a})$ holic $]$ faz ele ter necessariamente $[[\mathrm{X}](\mathrm{a})$ holism $]$.

Como conclusão de seu trabalho, a autora retoma propostas da $\mathrm{TO}$ e sua versão de correspondência (TC). Tomaszewicz alega que a possibilidade de um falante instituir um novo morfema para criar novas palavras simplesmente por vontade própria seria pouco econômica e contra-intuitiva, esquecendo, porém, de (a) considerar, na língua corrente, a alta aplicabilidade das novas partículas e (b) desconsiderar totalmente a contraparte semântica. Além disso, argumenta que a manutenção segmental e prosódica possibilita a utilização cada vez mais comum de cruzamentos, negando, portanto, a existência de splinters e postulando, na verdade, a ocorrência de cruzamentos advindos de outros cruzamentos. Na sua análise, formas com splinters emergem a partir da mesma demanda de restrições em jogo nos CVs, o que, para ela, constitui forte evidência empírica de que splinters, de fato, não existem.

\section{Uma análise otimalista sobre os blends em português}

A partir dos instrumentos da TO (PRINCE; SMOLENSKY, 1993) e da TC (MCCARTHY; PRINCE, 1995), Piñeros (2002) propõe uma análise da estrutura interna dos cruzamentos vocabulares em língua espanhola, cujo processo de formação, tal qual em português, não recebe tratamento homogêneo por parte dos estudiosos. Tal abordagem é, até onde se conhece, a primeira nessa perspectiva teórica. Assume, com Algeo (1977), a existência de dois tipos de cruzamentos: os telescopes e os portmanteaux; contudo, não analisa a formação do primeiro tipo, focalizando apenas a estruturação interna dos segundos. Os telescopes consistem na junção de duas palavras que aparecem em sequência na cadeia da fala, sendo um o determinado (DM) e outro, o determinante (DT), a exemplo de [kris.táno.la] 
$(<[$ kris.ta.lej.ra $]=$ cristaleira, $\mathrm{DM}+[$ es.pa.'no.la $]=$ espanhola, $\mathrm{DT})$. As palavras resultantes desse padrão são sempre menores que a soma das duas bases. No entanto, podem tanto ser maiores que cada uma das palavras-fonte quanto metricamente idênticas a elas. Os portmanteaux ${ }^{7}$ referem-se a um processo em que palavras são combinadas e caracterizadas por relações associativas a partir de propriedades segmentais em comum. Esse ponto de interseção pode ser um morfema e sons/porções fonológicas similares, como, por exemplo, os seguintes portmanteaux colhidos em Bogotá, na Colômbia: [lokombja] $(<$ loko] $=$ louco + $[$ kolômbja $]=$ Colômbia $)$ e $[$ ladronalds $](<[$ ladron $]=$ ladrão $+[$ makdonalds $]=$ Mc Donalds $)$, em que se verifica o compartilhamento de segmentos entre as palavras de base: [ko], no primeiro, e [dron] / [don], no segundo caso.

Em vez de duas palavras seguirem uma ordem sequencial, como as dos membros de uma composição, um portmanteau interpõe uma parte de uma das palavras à outra. Como consequência, há subtração de porções segmentais que pertencem exclusivamente a um dos vocábulos. O resultado, então, é a presença da ambimorfemia, verificando-se, portanto, a correspondência de muitos-para-um entre segmentos das formas de base e segmentos do cruzamento vocabular $(\mathrm{CV})$. É o caso de [bru.'xé.res $](<[$ bru.xa $]=$ bruxa $+[$ mu. 'xé.res $]=$ mulheres), em que $[\mathrm{u}] \mathrm{e}[\mathrm{x}]$ pertencem às duas palavras matrizes.

Por haver compartilhamento de formas (ambimorfemia), o cruzamento apresenta o mesmo número de sílabas e o padrão acentual de uma das palavras-fonte, mais especificamente aquela que funciona como núcleo. Isso explica o fato de [lo.'kom.bja] conservar a pauta acentual de [ko.'lom.bja] e não a de ['lo.ko]. Desse modo, cruzamentos e compostos diferem porque nestes não se observa nenhuma porção morfológica relacionada a dois morfemas, ou seja, neles não ocorre ambimorfemia.

Também com base na TC, Gonçalves (2005) analisa o CV, distinguindo-o da composição. Refuta, assim, os posicionamentos de Sandmann (1988), que afirma ser o cruzamento um tipo de composição em português, e de Henriques (2007), que entende o fenômeno como um processo de composição e derivação. Da mesma forma que Piñeros (2002) constata para o espanhol, Gonçalves (op. cit.) defende haver dois padrões de CV no português do Brasil: (a) um para os casos de impregnação lexical, em que as palavras matrizes apresentam algum tipo de semelhança fônica estrutural (os portmanteaux), e (b) outro para os

\footnotetext{
${ }^{7}$ Termo utilizado por Piñeros (2002) e Alves (1990) para batizar o processo de formação de novas palavras que não se identifica nem com a composição propriamente dita, nem tampouco com a derivação. Originalmente, o termo portmanteau (do francês 'cabide') foi introduzido por Hockett (1963) para denominar um morfe que corresponde a dois ou mais morfemas. Daí chamarem de portmanteaux os vocábulos cruzados que apresentam segmentos comuns às duas bases.
} 
dessemelhantes estruturalmente, em que as bases são totalmente diferentes do ponto de vista segmental e uma delas (ou ambas) sofre truncamento, ou seja, aparece encurtada no produto (os telescopes). Gonçalves (2005, p. 19) destaca ainda que "essa (des)semelhança fônica determinará o ponto de quebra" das palavras matrizes, chamando a atenção para o modo de interpretação dessa semelhança fônica, que deve ser vista não como mera presença de um segmento comum às bases, mas como uma semelhança em termos de posição na estrutura silábica.

Embora CVs e compostos tenham duas palavras servindo de input para a formação de uma terceira, o autor, ao analisar a estrutura interna dos primeiros, evidencia diferenças entre eles: (a) CVs participam de uma operação não concatenativa, em que a sucessão de bases pode ser rompida por sobreposições, enquanto compostos são formados por um processo linear, em que a ligação das bases se dá por encadeamento; (b) nos compostos, as bases são potencialmente livres, equivalendo a palavras morfológicas plenas, ao passo que, nos CVs, a combinação de palavras provoca ruptura na ordem linear - uma das bases se realiza simultaneamente com uma parte da outra -, portanto, não se pode afirmar que haja duas palavras morfológicas, pois, mesmo permitindo a recuperabilidade das bases, a integridade não é preservada; (c) para garantir fidelidade às formas de base, CVs exploram a possibilidade de um único segmento do vocábulo resultante da junção corresponder a dois ou mais segmentos das formas de base, ou seja, ser ambimorfêmico, minimizando os efeitos de opacidade no rastreamento das palavras matrizes. Em resumo, o autor considera cruzamentos produtos de um processo econômico que acessa informações fonológicas, como a posição do acento nas palavras tomadas como base, o grau de semelhança fônica e a natureza estrutural da sequência compartilhada entre elas, preservando, com isso, a estrutura prosódica e segmental das bases.

Analisando os blends do português do Brasil, com base na TC, Gonçalves (2005), seguindo Piñeros (2002), propõe a utilização das restrições de fidelidade MAX (FB-CV), MAX (FBmin-CV), e HEAD-MAX (FB-BL), a de marcação NOPWd* e a de alinhamento ALIGN $(\mathrm{M} \Leftrightarrow \mathrm{P})$, definidas abaixo, em (11): 
(11) MAX (FB-BL): cada elemento das formas de base deve apresentar um correspondente no CV. Essa restrição desfavorece o apagamento do domínio das duas formas de base (FB) para o domínio do cruzamento vocabular (CV).

MAX (FBmin): cada segmento da menor forma de base apresenta um correspondente no CV. Essa restrição desfavorece o apagamento do domínio da forma de base menor (FBmin) para o domínio do cruzamento vocabular (CV).

HEAD-MAX (FB-BL): todo o segmento da cabeça das formas de base (FB) tem um correspondente no cruzamento (CV), isto é, as sílabas tônicas das bases devem ser preservadas na palavra resultante.

NOPWd*: desfavorece recursividade no domínio da PWd (palavra prosódica), ou seja, outputs não podem apresentar nódulos PWD* (palavra prosódica complexa), isto é, mais de um acento lexical.

ALIGN $(\mathbf{M} \Leftrightarrow \mathbf{P})$ : prioriza o alinhamento, margem a margem, das palavras morfológicas (MWd) com a palavra prosódica (PWd); desfavorece, portanto, o desalinhamento das margens da categoria MWd no interior da categoria PWd resultante. Somente na formação de compostos regulares, em que todas as margens de MWd coincidem com as margens de $\mathrm{PWd}$, o alinhamento $(\mathrm{M} \Leftrightarrow \mathrm{P})$ é plenamente satisfeito.

Veja-se, na reprodução do tableau ${ }^{8}$ abaixo, em (12), proposto por Gonçalves (2005, p. 34), a aplicação dessas restrições na construção morfológica, já consagrada pelo uso, de sacolé, resultante do cruzamento de saco com picolé.

\footnotetext{
${ }^{8}$ No referido tableau, os colchetes demarcam margens de palavras prosódicas e as chaves, de palavras morfológicas.
} 


\begin{tabular}{|c|c|c|c|c|c|}
\hline$[\{$ 'saku $\}][\{$ piko'lE $\}]$ & $\begin{array}{c}\text { NO- } \\
\text { PWD } \\
*\end{array}$ & $\begin{array}{l}\text { ALIGN } \\
(\mathbf{M} \Leftrightarrow P)\end{array}$ & $\begin{array}{c}\text { MAX } \\
\text { (FB-CV) }\end{array}$ & $\begin{array}{l}\text { MAX } \\
\text { (Min) }\end{array}$ & $\begin{array}{c}\text { HEAD- } \\
\text { MAX }\end{array}$ \\
\hline a. $[\{\{$ pi.ko $\}\{$ 'sa.ku $\}\}]$ & & $* *$ & $\overline{l e ́}$ & & lé! \\
\hline$\circledast$ b. $[\{\{$ sa. $\{\underline{\text { co }}\} . ' I E\}\}]$ & & $* *$ & pi & & \\
\hline c. $[\{\{\mathrm{sa}\} .\{' 1 E\}\}]$ & & $* *$ & cop!ico & co & \\
\hline d. $[\{\{$ 'saku $\}][\{$ piko'IE $\}\}]$ & $* !$ & & & & \\
\hline e. $[\{\{$ sa $\}\{$ pi.ko.''IE\} $\}]$ & & $* *$ & $\mathrm{co}$ & $\mathrm{c!o}$ & \\
\hline
\end{tabular}

De acordo com esse tableau, o candidato (d) é sumariamente eliminado da disputa, já que realiza duas palavras prosódicas, sendo, portanto, um candidato ideal para o processo de composição, o que não é o caso. ALIGN $(\mathrm{M} \Leftrightarrow \mathrm{P})$, que advoga a favor da sobreposição de bases, mesmo que, para isso, seja necessário apagar alguns segmentos, não é capaz de arbitrar, visto todos os candidatos remanescentes apresentarem duas margens de MWd desalinhadas no interior do CV. A decisão, então, fica por conta dos restritores mais baixos. A forma (c) é descartada por eliminar mais segmentos, deixando o produto mais opaco. Os três candidatos remanescentes apagam dois segmentos, mas (e) deleta a sílaba átona da menor forma de base, violando, portanto, MAX (FBmin). Pelo tableau, observa-se que (b) sagra-se vitorioso, pois satisfaz, melhor que (a), a última restrição da hierarquia HEADMAX, que desfavorece apagamentos em tônicas (a forma em (a) deleta justamente a tônica de 'picolé'). Nas palavras de Gonçalves (2005, p. 33), o efeito da ambimorfemia, na formação de CVs, “[...] pode ser confirmado pela alta produtividade do padrão de formação que prioriza o compartilhamento de porções fonológicas. [...] Dessa maneira, constituem formações mais isoladas 'brasiguaio' e 'portunhol', casos de fusão lexical sem acesso à ambimorfemia". (GONÇALVES, 2005, p. $33)$.

A hierarquia NO-PWd* $>$ ALIGN $(\mathrm{M} \Leftrightarrow \mathrm{P})>>\operatorname{MAX}(\mathrm{FB}-\mathrm{CV})>>\operatorname{MAX}(\mathrm{FBmin})>>$ HEAD-MAX foi revista por Andrade (2008) por conta de a maioria dos dados projetar uma palavra prosódica com pé idêntico ao da palavra morfológica mais longa na borda direita, como ocorre nos seguintes exemplos: 
(13) ovonese, petralha, aborrescente apertamento, boilarina, rouberto

Dessa maneira, Andrade (2008) incluiu na hierarquia uma restrição que contempla a escansão e a direcionalidade do pé métrico nuclear. Para dar conta disso, propôs o restritor ALIGN D- $\Sigma$ (FBmax), D- $\Sigma$ (BL), formulado abaixo, em (14), obedecendo ao esquema de criação de restrições de Alinhamento Generalizado (ALIGN) postulado por McCarthy \& Prince (1995), no qual as restrições demandam que bordas e constituintes devam coincidir. Os tipos de constituintes que podem ser alinhados incluem tanto os de categoria prosódica - mora $(\mu)$, sílaba $(\sigma)$, pé $(\Sigma)$ e palavra prosódica $(\omega)$-, quanto os de categoria gramatical - afixo, raiz, radical e palavra morfológica.

(14) ALIGN, D- $\Sigma$ (FBmax), D- $\Sigma$ (BL): a borda direita do cruzamento é alinhada com o pé nuclear $^{9}$ da maior forma de base, ou seja, a palavra resultante deve apresentar o mesmo pé nuclear da base maior. A identidade diz respeito à estrutura silábica e aos segmentos constituintes.

O efeito dessa restrição, novidade da análise de Andrade (2008) em relação aos trabalhos de Gonçalves (2005) e Piñeros (2002), é estabelecer pés nucleares iterativos entre a maior palavra morfológica do input e a palavra prosódica projetada, o que pode ser observado no tableau em (16), abaixo, para a escolha do output ótimo do cruzamento ovonese (< "ovo" + "maionese"). Observe-se que a nova restrição dá conta da ordem das formas no interior do cruzamento:

\begin{tabular}{|c|c|c|c|c|c|}
\hline /'ovU/ + /maio'nezI/ & $\begin{array}{c}\text { NO- } \\
\text { PWd* }\end{array}$ & $\begin{array}{l}\text { ALIGN } \\
(\mathbf{M} \Leftrightarrow P)\end{array}$ & $\begin{array}{l}\text { MAX } \\
(\min )\end{array}$ & $\begin{array}{l}\text { MAX } \\
\text { (FB-) }\end{array}$ & $\begin{array}{c}\text { ALIGN, } \\
\text { D- } \Sigma\end{array}$ \\
\hline a. $[\{\{\mathrm{o.v}\{\underline{\mathbf{o}}\} . \operatorname{n\varepsilon } \mathrm{z} . \mathrm{zi}\}\}]$ & & $* *$ & & mai & \\
\hline b. $[\{\{o . v o\} .\{$ 'ne.zi $\}\}]$ & & $* *$ & & maio! & * \\
\hline c. $[\{\{$ may. $\{$ 'o $\} . v u\}\}]$ & & $* *$ & & nধzI! & $*$ \\
\hline d. $[\{[\{$ 'o.vu $\}][\{$ 'may.o $\}]\}]$ & $* !$ & $* *$ & & nezI! & $*$ \\
\hline e. $[\{\{$ may.o.'n $\varepsilon\} .\{v u\}\}]$ & & $* *$ & $0 !$ & zIo & $*$ \\
\hline f. $[\{\{$ may.o.'n $\}\{$ o.vu $\}\}]$ & & $* *$ & & $\varepsilon z I$ & $* !$ \\
\hline
\end{tabular}

\footnotetext{
${ }^{9}$ A restrição focaliza apenas o pé nuclear das palavras referidas, ou seja, aquele que projeta o acento lexical.
} 
Verifica-se nesse tableau que o candidato (d) é imediatamente excluído em NOPWd*, por projetar um nó na PWd resultante: $\mathrm{MWd}_{1}$ conserva o acento da forma menor, já que aplica a regra de neutralização na postônica final, e $\mathrm{MWd}_{2}$, devido à presença de uma sílaba pesada /mai/, adquire tonicidade e forma PWd independente. ALIGN $(\mathrm{M} \Leftrightarrow \mathrm{P})$ não é capaz de arbitrar porque todos os candidatos em disputa apresentam duas margens desalinhadas no interior da PWd. O concorrente (e) é banido em MAX (FBmin-BL), por deletar o segmento /o/ da forma mínima. A disputa, então, toma corpo em MAX (FB-BL), que elimina (b) e (c), visto ambos apagarem quatro segmentos da maior forma de base, um a mais que os candidatos (a) e (e), deixando a decisão para ALIGN D- $\Sigma$, que, por sua vez, descarta (e), um sério candidato em termos de estrutura, por não apresentar um pé à direita coincidente segmental e prosodicamente com o pé da palavra-matriz mais longa, 'maionese'.

Resumindo, cruzamentos emergem a partir da satisfação à restrição de marcação NOPWd*, que advoga contra a recursividade de acento na palavra prosódica projetada no cruzamento, e à de alinhamento, ALIGN $(\mathrm{M} \Leftrightarrow \mathrm{P})$, que milita a favor de alinhamentos perfeitos entre palavras morfológicas e prosódicas. Essas duas demandas desempenham papel preponderante na emergência de cruzamentos porque, juntas, impedem a formação de uma palavra prosódica complexa, já que, para preservar duas palavras morfológicas sob um único acento lexical, as formas ótimas lançam mão da sobreposição de bases. A interposição das bases na borda esquerda/direita da única palavra prosódica projetada garante o melhor alinhamento.

Consequentemente, quanto menos margens ficarem desalinhadas, mais segmentos poderão ser compartilhados, minimizando, desse modo, apagamentos desnecessários. Na fusão de duas bases, encurtamentos sempre ocorrem. Desse modo, a melhor acessibilidade ao input é garantida por meio da preservação das bases mais curtas, que tendem a se realizar plenamente na maioria dos cruzamentos, em função da exigência imposta por MAXmin.

Andrade (2008) observa, ainda, que muitos cruzamentos preservam o pé métrico nuclear da maior forma de base, o que levou à inclusão de outra restrição de alinhamento na hierarquia, ALIGN D- $\Sigma$ (FBmax). Essa restrição, além de favorecer o estabelecimento de pés iterativos entre as palavras morfológicas e a prosódica, concorre para a formação de cruzamentos em que a disposição das palavras matrizes se dê o mais adequadamente possível, uma vez que uma das características dos cruzamentos é que a ordem das bases não determina a posição da cabeça lexical; antes, é determinada pela manutenção do pé nuclear da forma mais longa, o que garante o melhor acesso às duas formas de base: a mais curta, pela 
preservação de seus segmentos, e a mais longa, pela manutenção de seu acento na forma final.

\section{Piri- e -guete: um estudo de caso}

Em "Sobre piris e guetes: análise morfológica das construções cunhadas a partir de splinters de 'periguete"' (CARVALHO; GONÇALVES, 2015), os autores lidam com os possíveis splinters piri- e -guete, descritos por eles como formas que têm origem na palavra periguete. Focando no comportamento das duas formas, percebem que atuam tanto em construções em que figuram como formas presas quanto como formas livres. Exemplos de formas livres aparecem em (16), a seguir:

(16) a. Sua piriguete, seu grupinho é cheio de piris metidas!!

(http://ask.fm/KaylaAlvess/answer/3881863354)

b. "eu serei a piriguete mais guete das guetes..."

(http://orkut.google.com/c44799741-t6046ebbdb708731a.html)

c. Piri, piri, piri

\section{Ex-guete, ex-guete, ex-guete}

Piri, piri, piri

Ex-guete, ex-guete, ex-guete

Tá tão santinha, mas não via hora de soltar a piriguete

(Música intitulada "Ex-guete", do Forró Pegado)

Primeiramente, Carvalho e Gonçalves (op. cit.) debruçam-se na origem da palavrafonte, periguete, e tentam, dessa maneira, descrever sua origem. Baseiam-se em Cândido (2013) para descrever processos que deram origem a tal forma. Para a autora, a palavra periguete forma-se a partir da adjunção do sufixo -ete à base perig- (atuante em formações como perigo e perigosa). Para Cândido (2013), o sufixo -ete, por sua vez, tem origem na palavra francesa monomorfêmica vedete, que, por conta de relações metafóricas com o grupo de dançarinas do apresentador Chacrinha, chamadas de 'chacretes', promove o surgimento de um novo sufixo que atribui às bases a ideia de dançarinas de $X$ ou fãs de $X$.

Quando do conhecimento de novas formações complexas com os dois ditos splinters (piri- e -guete), os autores observam que os formativos selecionam palavras do gênero feminino ou comuns-de-dois, predominantemente substantivos (17) e mais esporadicamente adjetivos (18):

$\begin{array}{llll}\text { (17) piriamiga } & \text { pirichefe } & \text { pirivizinha } & \text { piricriança } \\ \text { irmãguete } & \text { vovóguete } & \text { primaguete } & \text { mãeguete }\end{array}$




$$
\begin{array}{lll}
\text { pirisonsa } & \text { piripiranha } & \text { piripobre } \\
\text { amigaguete } & \text { pobreguete } & \text { sexyguete }
\end{array}
$$

Interessante notar a série de testes feitos de modo a controlar a produção de acento lexical nas construções estudadas. Primeiramente, diferentes textos contendo sentenças com os formativos foram formulados pelos autores para que, durante as entrevistas, fossem lidos pelos entrevistados. Após a leitura, eles respondiam perguntas sobre os textos, a fim de que fosse possível a produção espontânea das construções, e, dessa maneira, checar se eram produzidos como palavras fonológicas independentes ou não. $\mathrm{O}$ grupo amostral foi constituído de 20 falantes de ambos os sexos, com curso superior completo ou cursando e com Ensino Médio completo ou no último ano de estudo. Foi analisado o splinter piri- em suas formas presa e livre, enquanto guete teve apenas sua forma livre analisada. De modo a avançar com o trabalho, analisamos, neste artigo, nos mesmos moldes de Carvalho e Gonçalves (2015), produções em que o splinter -guete constitui forma presa. A seguir, são reproduzidos os textos utilizados pelos autores nas entrevistas.

Na Igreja, todos julgavam ela, pensavam que ela não devia ser daquele jeito. "Ela não devia estar aqui", diziam eles, "Piricrente", era como eles chamavam ela. Depois de tudo o que eles tinham passado, ela ainda tinha coragem de agir daquela forma e fingir que nada acontecia, tinha coragem de ser aquela pirisonsa. Até que no final, expulsaram ela de lá.

Pirigótica, assim Renata era chamada. Falavam que ela não se encaixava em nenhuma tribo. Estava sempre de preto, mas não eram vestidos longos, nem botas e nem coletes. Ela gostava mesmo de 'baby-look' e shortinho curto. $\mathrm{Na}$ verdade, ela se sentia uma pirigata.

Foi uma confusão danada. Começou quando chamaram de pirivizinha, e depois de piripobre. Ela já quase não aguentava mais, era muita humilhação. Todo dia alguém jogava alguma piada, tentava diminuir ela. Quando a confusão finalmente acabou ela se afirmou: "E qual o problema? Sou isso tudo e mais, sou pirigostosa".

Ela tinha raiva daquela piri. Odiava aquela menina com todas as forças. A piri sempre reclamava dela para todo mundo, falava mal dela. Não existia uma boa relação entre elas.

"Guete, vem cá" - Joana chamou a amiga. Ela se referia à amiga sempre assim, era a forma carinhosa de elas se chamarem, não tinha outra palavra, era 'Guete'.

Os autores chegaram à conclusão de que - guete (forma presa) continua mantendo a pauta acentual que exibe na palavra-fonte, com acento lexical na sílaba à esquerda, constituindo um troqueu (* .). Já piri- (forma presa) ganha pauta acentual própria e variável, a 
depender da posição do acento na palavra seguinte. Quando realizado como forma livre, possui pauta acentual diferente, sendo categoricamente produzido como oxítono, com acento em [ri], formando, assim, um iambo (. *): [pi.'ri].

\section{Enfim, splinters são cruzamentos de cruzamentos?}

Se, na proposta de Tomaszewicz (2008), splinters, na verdade, são cruzamentos de cruzamentos, a hierarquia proposta para os cruzamentos vocabulares do português, resenhada na seção 3, deve garantir a emergência das construções tanto como piri- quanto com -guete, descritas na seção 4. Vejamos se isso de fato acontece analisando algumas das construções de nosso corpus. Comecemos com 'vovoguete', uma das mais conhecidas:

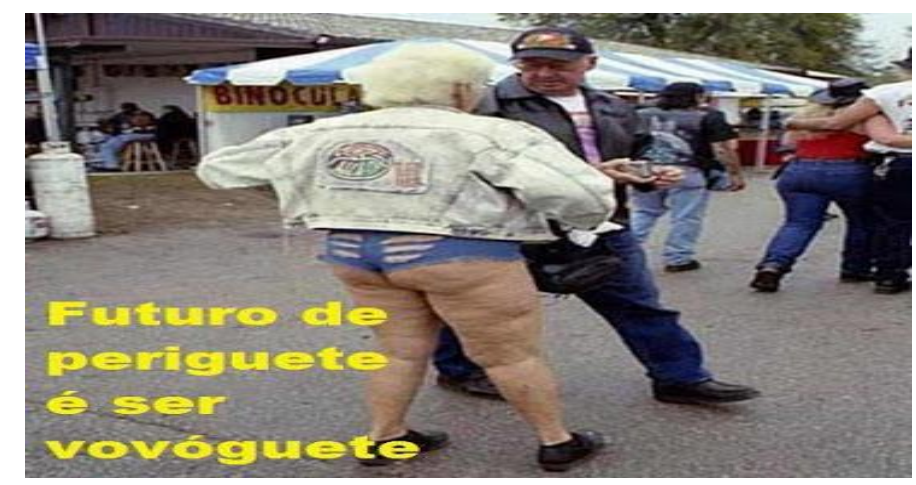

https://www.google.com.br/search?q=vovoguete+imagem\&tbm. Acesso em: 24 dez. 2015

Assumimos, na seção 3, seguindo Piñeros (2002), que NO-PWd* e ALIGN(MP) são as restrições mais altas da hierarquia porque sua satisfação permite que cruzamentos se realizem sob um único acento e deixem apenas uma margem de MWd desalinhada. Em relação aos fatores que determinam haver fronteira de PWd em português, tomamos por base as características a seguir, adaptadas de Vigário (2002): (a) pausa sensível entre os pés constituintes; (b) alongamento interssilábico; (c) alteração nos padrões de alternância rítmica, geralmente ocasionada por colisões acentuais (clashes); (d) encontro de vogais ou consoantes que produz efeito acústico desagradável; (e) abertura de vogais médias na posição pretônica; (f) neutralização de átonas postônicas finais; (g) presença de determinados padrões estruturais de constituição silábica que tendem a atrair o acento, como, por exemplo, sílabas pesadas, constituídas de vogais e ditongos nasais, encontrados apenas na borda direita da palavra; e (h) presença de morfemas portadores de acento próprio, como a maioria dos prefixos e os sufixos -mente, -zinho e -íssimo. 
Assim sendo, a forma que emerge, quase sempre realizada com duas vogais abertas nas sílabas iniciais, e grafada com acento agudo na segunda vogal, tanto na figura acima quanto em outras ocorrências encontradas na Internet, perde para a rival com vogal fechada já na primeira restrição da hierarquia ${ }^{10}$ :

\begin{tabular}{|c|c|c|}
\hline /vo'va/ + /pEri'getI/ & $\begin{array}{l}\text { NO- } \\
\text { PWd* }\end{array}$ & $\begin{array}{l}\text { ALIGN } \\
(M \Leftrightarrow P)\end{array}$ \\
\hline a. $\left[\left\{\{\right.\right.$ vo.vo $\}\left\{\right.$ 'ge. $\left.\left.\left.f_{\mathrm{I}}\right\}\right\}\right]$ & & $* *$ \\
\hline b. $[\{\{$ 'vวvว $\}][\{$ 'ge.tfI $\}\}] \odot$ & $* !$ & $* *$ \\
\hline
\end{tabular}

Como se vê, a hierarquia seleciona o candidato incorreto, pois a forma que emerge se realiza numa palavra prosódica independente, o que se evidencia não apenas pela abertura da média posterior, como também pela retração acentual, ocasionada pela colisão da sílaba acentuada de 'vovó' (final) com a sílaba acentuada de 'guete' (inicial). O símbolo : indica que o vencedor é preterido pelo falso ganhador. Outros dados do corpus também ficam mal resolvidos nessa análise porque a forma à esquerda constitui palavra prosódica independente: (21) Velhaguete: a forma 'velha' preserva a abertura da média pretônica, o que sinaliza a manutenção do acento e a realização do todo sob duas palavras prosódicas. O mesmo acontece com 'sexyguete';

Mãeguete: a forma 'mãe' apresenta ditongo nasal, estrutura só tolerada em final de palavra prosódica;

Crenteguete: a primeira PWd realiza a vogal final como [I], promovendo o alçamento da postônica final e o consequente acionamento da regra de neutralização. O mesmo raciocínio vale para 'pobreguete', esta última com abertura adicional na média pretônica;

Irmãguete: por haver clash, há retração acentual em 'irmã', fazendo com que a primeira sílaba passe a dominante e a segunda, a dominada (['iymẽ'getgi I])'.

Em todos esses casos, ocorre violação à restrição mais importante da hierarquia: NOPWd*, o que inviabiliza tratar essas construções como cruzamentos de cruzamentos, já que não se comportam como cruzamentos prototípicos. Vejamos, a seguir, a situação de

\footnotetext{
${ }^{10}$ Os tableaux utilizados na análise apresentam as seguintes convenções: (a) os colchetes demarcam os limites da PWd; (b) as chaves demarcam os limites da $\mathrm{MWd}_{1}$ e da $\mathrm{MWd}_{2}$ no interior da PWd; (c) o ponto demarca as fronteiras silábicas da $\mathrm{MWd}^{*}$; (d) os inputs aparecem representados fonologicamente e os outputs, foneticamente; (e) segmentos ambimorfêmicos aparecem em negrito e estão sublinhados
} 
'coroguete', também bastante usual, tanto na fala quanto em ambiente de Internet, uma vez que foi cunhada pelo conhecido apresentador Sílvio Santos (SBT):

(22) O que é coroguete que o Silvio Santos fala tanto?

É uma palavra que ele inventou, é tipo uma mistura de Piriguete com coroa (velha).

Ai ele inventou $=$ Coroguete

https://br.answers.yahoo.com/question/index?qid=20140316190634AAPWueA.

Acesso em: 24 dez. 2015

A forma que de fato emerge na língua é preterida por outra mais transparente, em que toda palavra 'coroa' aparece no interior do cruzamento. Nesse caso, a decisão cabe às restrições mais baixas, uma vez que NOPWd* e ALIGN $(\mathrm{M} \Leftrightarrow \mathrm{P})$ são satisfeitas:

\begin{tabular}{|l|c|c|c|c|}
\hline$/$ ko'roa/ + /pEri'getfI/ & $\begin{array}{c}\text { NO- } \\
\text { PWd* }\end{array}$ & $\begin{array}{c}\text { ALIGN } \\
(\mathbf{M} \Leftrightarrow \mathbf{P})\end{array}$ & $\begin{array}{c}\text { MAX } \\
(\mathbf{m i n})\end{array}$ & $\begin{array}{c}\text { MAX } \\
\text { (FB-CV) }\end{array}$ \\
\hline a. $[\{\{\text { ko.row.wa }\} .\{\text { 'ge.tI }\}\}]^{\text {- }}$ & & $* *$ & & pE.ri \\
\hline b. $[\{\{$ ko.ro $\} .\{$ 'ge.fI $\}\}]:$ & & $* *$ & $* !$ & a / pE.ri \\
\hline
\end{tabular}

A forma que de fato se realiza na língua perde a vogal final de 'coroa' para ficar metricamente mais próxima da palavra de base mais longa, respeitando o número de sílabas de 'periguete' (quatro) até porque explora a identidade do tepe na segunda sílaba, uma vez que esse segmento é compartilhado pelas duas bases. No entanto, viola MAX-min e é nesse momento da avaliação que perde para a rival que não constitui forma em uso.

Se admitirmos a ambimorfemia de [c], no intuito de tentar emergir a forma (b) na avaliação por ALIGN $(\mathrm{M} \Leftrightarrow \mathrm{P})$, ainda assim haveria duas margens desalinhadas, como vê na representação [\{ ko. $\{$ ro $\} . ' g \varepsilon . t f i\}\}]$. Nesse caso, para salvar esse candidato, teríamos de fazer uso de várias correspondências não idênticas, associando [k] com [p] e [o] com [i] duas vezes, o que não parece descrever com naturalidade a formação. Mais uma vez, temos um perdedor não selecionado pelo ranking proposto.

A situação é um pouco mais delicada quando analisamos os dados piri-X. Nesse caso, há sistemática violação ao restritor que milita em favor do alinhamento da borda direita do cruzamento com o pé nuclear da maior forma de base (nesse caso, 'periguete'), ainda que essa demanda seja a mais baixa da hierarquia. Observando o tableau a seguir, com a análise de 'pirigótica', em que o vencedor correto é selecionado, podemos admitir que a escolha da piri-, 
em detrimento de -guete, constitua estratégia para satisfazer as demandas mais altas, NOPWd* e MAXmin:

\begin{tabular}{|c|c|c|c|c|}
\hline /'gว.ti.ka/ + /pEri'getgI/ & $\begin{array}{c}\text { NO- } \\
\text { PWd* }\end{array}$ & $\begin{array}{l}\text { ALIGN } \\
(\mathrm{M} \Leftrightarrow P)\end{array}$ & $\begin{array}{l}\text { MAX } \\
\text { (min) }\end{array}$ & $\begin{array}{c}\text { MAX (FB- } \\
\text { CV) }\end{array}$ \\
\hline a. $[\{\{$ 'go.tgi.ka $\}][\{$ 'ge.tfi $\}\}]$ & $* !$ & $* *$ & & pEri \\
\hline b. $[\{\{$ go.tgi $\} .\{$ 'ge.tgI $\}\}]$ & & $* *$ & ga! & ga / ge.tfi \\
\hline c. $[\{\{$ pi.ri $\}\{$ 'go.ti.ka $\}\}]$ & & $* *$ & & ge.tfi \\
\hline d. $[\{\{$ pi.'ri $\}][\{$ 'go.ti.ka $\}\}]$ & $* !$ & $* *$ & & \\
\hline e. $[\{\{$ pi.ri $\}\{$ 'gว.tgi $\}\}]$ & & $* *$ & $\mathrm{ka} !$ & \\
\hline
\end{tabular}

Observe que o rival em (d), praticamente idêntico a (c), acentua a sílaba final de piri- e é eliminado de pronto, com o agravante de apresentar colisão acentual, o que não está em jogo na avaliação (constituiria uma violação à restrição NOCLASH). Poderíamos nos questionar se, de fato, há apenas um acento na forma vencedora ou se, na verdade, o acento da forma livre 'piri', tal como vimos na seção 4, é deslocado para a sílaba imediatamente anterior, como alternativa para resolver o clash: $[\{\{$ 'pi.ci $\}][\{$ 'go.tfi.ka $\}\}]$. Observamos alternância rítmica nos seguintes casos, em que a sílaba dominante de 'piri' está em negrito, tanto quanto a tônica da segunda MWd:

\section{piricriança pirigostosa pirifunkeira piripiranha pirigorda pirigata pirigringa piripunk}

A audição atenta dos dados possibilitou observar que, na grande maioria das formações com piri-, ocorrem três características importantes para o reconhecimento de fronteira de palavra prosódica: (i) pausa sensível entre os pés constituintes, (ii) alongamento interssilábico e, em consequência, (c) alteração nos padrões de alternância rítmica, ocasionada por colisões acentuais (clashes). Em 'piripiranha', por exemplo, os falantes tendem a alongar o segundo [i], estabelecendo, com isso, uma fronteira entre os pés métricos da palavra complexa e essa tendência se repete nas demais formações em que a segunda sílaba do splinter é a mais forte.

No caso de 'pirigringa', uma pausa separa os dois pés, o mesmo acontecendo com os demais casos em que a primeira sílaba de piri- é a dominante. Desse modo, a representação $[\{\{$ pi.ri $\}\{$ 'gJ.tfi.ka $\}\}]$ não é inteiramente adequada, pois a sílaba inicial porta acento, criando 
domínio fonológico próprio e promovendo o isomorfismo entre $\mathrm{PWd}$ e $\mathrm{MWd}$ : $[\{\{$ 'pi.ri $\}][\{$ 'go.tyi.ka $\}\}]$. Além disso, a maioria das formas piri-X é grande demais para se realizar sob um único acento:

$$
\begin{array}{llll}
\text { pirifunkeira } & \text { pirigostosa } & \text { pirigótica } & \text { pirilésbica piripagodeira pirivizinha } \\
\text { pirireligiosa } & \text { pirirockeira } & \text { piripiranha pirivagabunda }
\end{array}
$$

Assumimos, então, que as formas piri-X sistematicamente violam a condição mais alta da hierarquia e, com isso, não passam pelo ranking, sendo preteridas por outras que não se realizam na língua. Desse modo, das duas, uma: ou a hierarquia não está correta ou essas construções não são cruzamentos de cruzamentos, como preconiza Tomaszewicz (2008), sendo, na verdade formações cunhadas a partir de unidades morfológicas chamadas splinters. Na nossa opinião, essa segunda opção parece a mais acertada.

\section{Considerações finais}

Neste artigo, focalizamos a projeção de sequências não-morfêmicas à condição de splinters, defendendo, ao contrário de Tomaszewicz (2008), a relevância dessa unidade morfológica no português do Brasil. Para argumentar ainda mais em favor de nossa proposta, consideremos a palavra 'paitrocínio', utilizada na seguinte manchete publicada no site do Globo Esporte, em 08/10/2015:

$$
\text { "Paitrocínio" de mais de R } \$ 90 \text { mil leva brasileiro a inédita vaga olímpica }
$$

Rafael Andrade mal podia acreditar que um sonho de 20 anos enfim se tornava realidade. Na quinta-feira, ele se tornou o primeiro brasileiro a se classificar para a disputa da ginástica de trampolim de uma edição de Olimpíadas. O goiano de 29 anos começou a colher os frutos de muita dedicação, dele e de seus pais. No caminho para ser o melhor brasileiro no Mundial de Odense e ficar com a única vaga de país-sede da modalidade para os Jogos do Rio de Janeiro 2016, Rafael teve de adiar os planos de montar um consultório odontológico e contou com um "paitrocínio" de mais de R\$ 90 mil para bancar 15 meses de preparação na Europa. (http://globoesporte.globo.com/trampolimacrobatico/noticia/2015/11/paitrocinio-de-mais-de-r-90-mil-leva-brasileiroineditaa.html. Acesso em: 02 fev. 2016)

É provável que quem cunhou essa palavra, já bastante consagrada pelo uso, tenha se aproveitado da semelhança da sílaba 'pa' com a palavra 'pai', explorando o aludido recurso da ambimorfemia, ao fundir as duas bases na margem esquerda do cruzamento. Com isso, o restante da construção morfológica original, a sequência -trocínio, acabou sendo tomada por 
um formativo com o significado de "financimento, subvencionamento". Consequentemente, a troca de parte de uma palavra por outra, mantendo o restaste inalterado, criou condições eficazes para (a) desencadear novas associações e, com isso, (b) formar séries de palavras com igual significado.

Como mostra Gonçalves (2011), as palavras em (28), a seguir, originaram-se do cruzamento vocabular 'paitrocínio' e, “por analogia, é possível especificar qualquer agente financiador do patrocínio pela substituição da sequência à esquerda, o que leva -trocínio a funcionar como splinter e a participar de um esquema de formação de palavras" (GONÇALVES, 2011, p. 81) como (29), a seguir ${ }^{11}$ :

$\begin{array}{ll}\text { CAPEStrocínio } & \text { BOBstrocínio } \\ \text { mãetrocínio } & \text { avôtrocínio } \\ \text { irmãotrocínio } & \text { autotrocínio }\end{array}$

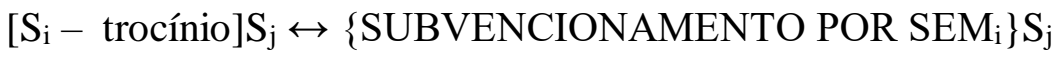

A recorrência de -trocínio e a utilização de formas transparentes na primeira posição (nesse caso, a de radical) cria condições ótimas para o isolamento das partes, o que atua em consonância com os princípios 1, 2 e 5, propostos por Nida (1949, p. 45), para a identificação de morfemas, explicitados em (30), a seguir. Observe-se que o princípio 5 faz referência direta à questão da descontinuidade morfológica:

(30) Princípio 1 - "as divisões devem moldar-se às relações significativas";

Princípio 2 - "as divisões são feitas na base da substituição de unidades";

Princípio 5 - "entre uma divisão em constituintes imediatos contínuos e outra em constituintes imediatos descontínuos, a preferência deve ser dada à primeira análise”.

Portanto, formas outrora caracterizadas pelo entranhamento de duas bases podem, com a fixação de um padrão, adquirir condições ótimas para a isolabilidade das partes, o que nos autoriza a reivindicar o estatuto de morfema não apenas para sequências como piri- e -guete, aqui analisadas com mais vagar, mas também para -trocínio, -drasta, caipi-, -nejo e tantas outras, que se tornaram recorrentes após a popularização dos cruzamentos de que participaram.

\footnotetext{
${ }^{11}$ A notação aqui utilizada é, em essência, a proposta por Booij (2010). SEM representa o significado do constituinte relevante. A seta dupla expressa que há correspondências entre (partes de) a representação formal e a semântica, expressa pela co-indexação (as letras ${ }_{\mathrm{i}} \mathrm{e}_{\mathrm{j}}$, subscritas). A representação à esquerda da seta dupla é a especificação formal dos substantivos $(\mathrm{S})$ terminados em -trocínio. A representação à direita é do polo significado, sempre representado entre chaves e em maiúsculas.
} 
GONÇALVES, Carlos Alexandre; CARVALHO; Wallace Bezerra de; ANDRADE, Katia Emmerick. Are splinters "blends formed by blends"? Rethinking the rules of this constituent in portuguese language. Revista do GEL, v. 13, n. 1, p. 132-156, 2016.

Abstract: Our goal in this paper is to check, for Brazilian Portuguese (BP), the validity of the Tomaszewicz's proposal (2008), for whom splinters do not constitute units of morphological analysis; but they are actually "blends formed by blends". To do so, we based on the optimistic analysis of Gonçalves (2005) and Andrade (2008) about lexical blending noting how new formations, with what we have been calling splinters (GONÇALVES, 2011; GONÇALVES, 2013; ANDRADE, 2014) can be successful in the ranking of imitations proposed. Therefore, we sought to check, with Brazilian Portuguese data, if the idea that splinters are blends formed by blends is actually supported in our language.

Keywords: Morphology. Lexical Blending. Optimality Theory. Splinter.

\section{Referências}

ADAMS, V. An introduction to modern English word-formation. English Language Series 7. London: Longman, 1973.

ALVES, I. M. Neologismo: criação lexical. São Paulo: Ática, 1990.

ANDRADE, K. E. Proposta de continuum composição-derivação para o português do Brasil. 2013. 163 f. Tese (Doutorado em Letras Vernáculas) - Universidade Federal do Rio de Janeiro, Rio de Janeiro, 2013.

Uma análise otimalista unificada para mesclas lexicais do português do Brasil. 2008. 131 f. Dissertação (Mestrado em Letras Vernáculas) - Universidade Federal do Rio de Janeiro, Rio de Janeiro, 2008.

BAUER, L. A Glossary of Morphology. Washington: Georgetown Univ. Press, 2004. The borderline between derivation and compounding. In: DRESSLER, W. et al. (ed.). Morphology and its demarcations. Amsterdam / Philadelphia: John Benjamins Publishing Company, 2005. p. 79-93.

BENUA, L. Identify effects in morphological truncation. In: BECKMAN, J. (ed.). Papers in Optimality Theory, 18 (1), p. 77-136, 1995.

BOOIJ, G. Construction Morphology. Amsterdam / Philadelphia: John Benjamins Publishing Company, 2010.

CÂNDIDO, B. F. Formações X-ete no português do Brasil: uma análise construcional. 2013. 76 f. Dissertação (Mestrado em Letras Vernáculas) - Universidade Federal Rio de Janeiro, Rio de Janeiro, 2013 
CARVALHO, W. B.; GONÇALVES, C. A. V. "Sobre piris e guetes": análise morfológica das construções cunhadas a partir de splinters de "periguete". Fórum Linguístico, Florianópolis, v. 12, n. 4, p. 930-944, out./dez. 2015.

GONÇALVES, C. A. V. Blends lexicais em português: não-concatenatividade e correspondência. Veredas (UFJF), Juiz de Fora, v. 14, n. 1, p. 16-35, 2005.

Paitrocínio, tecno-macumba, maridoteca: o comportamento das formas combinatórias no português do Brasil. Revista da ABRALIN, Curitiba, v. 10 (2), p. 67-90, jul./dez. 2011.

Na sextaneja com a caipifruta da mãedrasta: o estatuto morfológico dos splinters no português brasileiro contemporâneo. Diadorim, Rio de Janeiro, v. esp., n. 13, p. 139-158, 2013.

HENRIQUES, C. C. Morfologia. Rio de Janeiro: Elsevier, 2007.

KASTOVSKY, D. Astronaut, astrology, astrophysics: about combining forms, classical compounds and affixoids. In: MCCONCHIE, R. W. et alii. (eds.). Selected Proceedings of the 2008 Symposium on New Approaches in English Historical Lexis (HEL-LEX 2). Somerville: Cascadilla Proceedings Project, p. 1-13, 2009.

MCCARTHY, J.; PRINCE, A. Faithfulness and reduplicative identity. Rutgers: Rutgers University, 1995.

NIDA, E. A. Morphology the descriptive analysis of words. Ann Arbor: The University of Michigan Press, 1949.

PIÑEROS, C. E. The creation of portmanteaus in the extragrammatical morphology of spanish. Iowa: University of Iowa, 2002.

PRINCE, A.; SMOLENSKY, P. Optimality Theory: constraint interaction in generative grammar. Rutgers University / University of Colorado: New Brunswick, 1993.

SANDMANN, A. J. Formação de palavras no português brasileiro contemporâneo. Curitiba: Scientia et labor; Ícone, 1988.

TOMASZEWICZ, E. Novel words with final combining forms in English: a case for blends in word formation. Poznań Studies in Contemporary Linguistics, 44(3), p. 363-378, 2008.

VIGÁRIO, M. Prosodic word in european portuguese. Coimbra: Almedina, 2002.

Submetido em 02/02/2016

Aceito em 25/04/2016 